\title{
Role of MRI for the Detection of Prostate Cancer
}

Richard C. Wu ${ }^{1,2}$, Amir H. Lebastchi ${ }^{3}$, Boris A. Hadaschik ${ }^{4}$, Mark Emberton ${ }^{5}$, Caroline Moore ${ }^{5}$, Pilar Laguna ${ }^{6}$, Jurgen J. Fütterer ${ }^{7}$, Arvin K. George $^{8^{*}}$

1. Department of Urology, E-Da Hospital, Kaohsiung, Taiwan

2. College of Medicine, I-Shou University, Kaohsiung, Taiwan

3. Department of Urology, University of Southern California, Los Angeles, California, USA

4. University Hospital Heidelberg and German Cancer Research Center, Heidelberg, Germany

5. Division of Surgery and Interventional Science, University College London, London, UK

6. Department of Urology, Medipol University Research Hospital, Istanbul, Turkey

7. Department of Radiology and Nuclear Medicine, Radboud University Medical Center, Nijmegen, The Netherlands

8. Department of Urology, University of Michigan, Ann Arbor, Michigan, USA

* Corresponding author

\begin{abstract}
The use of multiparametric MRI has been hastened under expanding, novel indications for its use in the diagnostic and management pathway of men with prostate cancer. This has helped drive a large body of literature describing its evolving role over the last decade. Despite this, prostate cancer remains the only solid organ malignancy routinely diagnosed with random sampling. Herein, we summarize the components of multiparametric MRI and interpretation, and present a critical review of the current literature supporting is use in prostate cancer detection, risk stratification, and management.
\end{abstract}

\section{Introduction}

Prostate cancer ( $\mathrm{PCa}$ ) represents the most common solid organ malignancy in men with almost 1.3 million new cases diagnosed globally in 2018[1] . However, despite a high incidence, many will be asymptomatic, and only a minority will result in PCa death.[2] Accurate identification of men who are at risk of metastasis or death remains a challenge. As such, a large proportion of men will undergo definite treatment, potentially without ever realizing long-term benefit [3]. 
Prostate-specific antigen (PSA) remains the gold-standard for screening and given its poor specificity, its utility has been debated [4]. A trans-rectal ultrasound (TRUS) guided systematic biopsy (SBX) is the conventional next step in the diagnostic pathway. However, TRUS itself has a limited role in detecting PCa as most hypoechoic lesions are benign with even up to $50 \%$ of palpable tumors being invisible on imaging.[5] Major concerns of SBx include sampling error by which 20-50\% clinically significant (cs) PCa may be missed - the majority of which are located in the anterior gland and prostatic apex.[6] Additionally, given its random nature, SBx identifies a large number of indolent cancers and exposes the patient to the risk of additional testing and procedures which can result in unnecessary stress, morbidity and waste of resources.

Multiparametric MRI (mpMRI) has been increasingly used in a number of clinical settings. It has been employed as a particularly useful tool to help address the shortcomings of the established pathway described above. It is composed of anatomical sequences (T1-weighted [T1W] and T2-weighted [T2W] images), combined with functional sequences, including dynamic contrast-enhanced MRI (DCE-MRI) and diffusion-weighted imaging (DWI). Its application has been transformative in the detection, localization, and staging of $\mathrm{PCa} .[7,8]$

After an initial rise in the incidence of PCa secondary to widespread PSA screening, it has stabilized or even declined in some high-income countries.[9] This has been partly attributed to a number of novel risk stratification tools including mpMRI which have proven to have better discriminative ability prior to prostate biopsy.[10] We aim to provide a critical appraisal of the literature with regards to the role of $\mathrm{mpMRI}$ in the PCa diagnostic pathway. 


\section{Principles of Multiparametric Prostate MRI}

Currently, 1.5 and 3 Tesla $(T)$ are the two most common magnet-field strengths utilized in clinical prostate MRI. A 3T MRI, in most scenarios, will provide improved spatial resolution due to the higher signal-to-noise ratio but will also amplify the presence of artefacts (Figure 1).[11] Although subjective, image quality at $1.5 \mathrm{~T}$ is generally lower than at 3T, the Prostate Imaging - Reporting and Data System (PIRADS) scores are similar in the two groups without an endo-rectal coil (ERC).[12] Additionally, the utilization of an ERC can result in up to tenfold improvement in signal-to-noise ratio.[13] Though the use of an ERC provides better image quality and results in greater sensitivity to detect prostate cancer, the specificity can decrease and it increases unique opportunities for image degradation (e.g. air, malpositioned coil, gland deformation).[14] Further studies aiming a comparison between 1.5T mpMRI with ERC and 3T mpMRI without ERC showed no significant differences in diagnostic accuracy.[15] Furthermore, the use of ERC is associated with increased discomfort and preparation time.[11] Contemporary recommendations in PIRADS states that both 1.5T and 3T without the use of an ERC may generate satisfactory results.[16]

\section{Anatomic T1-weighted and T2-weighted MRI}

The T1W and T2W phases provide predominantly anatomic information. While the T1W images can detect hemorrhage (mostly caused by prior biopsy), T2W images provide sufficient resolution to examine the zonal anatomy and provide insight with regards to the local staging.[17] Hemorrhage will manifest as high signal intensity (SI) in T1W images and low in T2W which can obscure the diagnosis of underlying disease (Figure 2).[18] Although there is no consensus to conclude the best interval between prostate biopsy and MRI, many clinicians suggest a 6-12 week time interval for better interpretation.[19] Though there is widespread acceptance of evidence supporting MRI prior to biopsy, which can avoid the hemorrhage and post-biopsy artifact, a large proportion of biopsies are still performed without a prior MRI due to insurance coverage or access to reliable, high quality imaging.

Given its high spatial resolution, the peripheral, transitional, and central zone can be identified as high, heterogeneous and low SI in T2W images, respectively.[20] A lower heterogenous SI lesion in the peripheral zone may be considered as suspicious for tumor.[21] However, T2W alone has high sensitivity but low specificity in detecting PCa; also, many benign lesions, i.e. prostatitis and fibrosis, also generate low SI which mimic PCa.[20] Morphologic features such as non-circumscribed or lentiform structures are more likely to be malignant lesions and are used for further 
differentiation. The heterogeneous SI in transitional zone makes diagnosis a greater challenge and interpretation relies more so on morphology. Functional sequences should be used in conjunction with T2W to increase the accuracy of PCa detection.

\section{Diffusion-weighted image}

DWI quantifies the random displacement of water molecules, known as diffusion or Brownian motion, which is affected by the cellular environment. The b-value is the foundation of DWI which represents the strength of the diffusion sensitizing gradient and is measured in seconds per square millimeter. A high b-value setting can suppress benign prostate tissue and increase the contrast between normal and abnormal prostatic tissue, predominantly suspicious for cancer.[22] The latest PIRADS version, v2.1, recommends image acquisition at a b-value of 1400-2000 s/mm2.[16] However, high b-value, e.g. $2000 \mathrm{~s} / \mathrm{mm} 2$, has very low signal-to-noise ratio while $b$-value of $1000 \mathrm{~s} / \mathrm{mm} 2$ has high signal-to-noise ratio but lower normal tissue suppression.[23] An apparent diffusion coefficient (ADC) map is designed to overcome this situation by calculating at least two different b-values. On the image, an area with limited diffusion coefficient showed high SI in the DWI and low SI in the $A D C$ map. PCa tissue tends to have higher cellularity which results in impeded diffusion of water molecules, demonstrating high SI in b-value and low SI in ADC on DWI.[24] A schematic of MR images according to PIRADS is noted in Figure 3.

\section{Dynamic contrast-enhanced MRI}

DCE-MRI reflects the vascular distribution and capillary permeability of tissue, a surrogate for neoplastic neovascularization. The features of PCa presenting on DCEMRI demonstrate an earlier intense enhancement than normal prostatic tissue.[25] A fast $(2-3 \mathrm{cc} / \mathrm{s})$ injection of gadolinium-based contrast agent and high temporal resolution acquisition ( $<15 \mathrm{~s}$ ) is essential.[16] However, there are pitfalls in DCE-MRI interpretation such as prostatitis and BPH nodules that may exhibit similar DCE characteristics.[20] Although PI-RADS v2 recommends DCE-MRI as essential in every patient unless there is a contraindication, the evidence supporting its necessity is controversial.[19] Moreover, there are issues related to the utilization of gadoliniumbased contrast agent as time considerations and the risk of adverse events, including nephrogenic systemic fibrosis and accumulation.[26] In response, the biparametric MRI (bpMRI) protocol was proposed to exclude the routine utilization of DCE-MRI during screening or follow-up and may serve as future standard of care protocol for screening.[27,26] 



\section{MRI Interpretation}

Initial guidance for prostate MRI interpretation was limited with no standardized criteria available. Radiologists historically used Likert scale-based reports which though correlating with cancer detection and Gleason score, varied by institution. The lack of criteria resulted in inter-reader variability and made it challenging to compare outcomes across cohorts.[28]

The PIRADS document represents the current standard for image acquisition and interpretation based on expert consensus. It is a multinational, multidisciplinary consortium supported by both the American College of Radiology and European Society of Urogenital Radiology.[29] The accuracy and reproducibility of this first generation system(sensitivity and specificity $\mathrm{f} 0.78$ and 0.79 respectively) has been validated in a meta-analysis.[30] Although PI-RADS provided a common reporting language, several issues remained. The overall score was not standardized, with some studies publishing a summary score from each sequence, from 3 to 15 while others using a 1 to 5 overall score.[31,32] Version 2 was released in 2015 to address these deficiencies.[33] The major changes included the introduction of the dominant sequence in different anatomical zones: $\mathrm{DWI}$ and $\mathrm{T} 2 \mathrm{~W}$ in peripheral and transitional zone, respectively. This version also limited the weight of DCE imaging.[34] A recent meta-analysis reported a pooled sensitivity and specificity of 0.89 and 0.73 with a significant sensitivity increasing when it comes to head-to-head comparison.[35] A less costly and abbreviated acquisition protocol termed bpMRI which requires only T2W images and DWI parameters, high b-value DWI and ADC maps, has been proposed.[26] Validation studies have shown there are benefits to bpMRI alone, or in combination with clinical variables such as PSA and/or PSA density to detect csPCa in a biopsy-naive cohort.[36]

Inter-observer variability has been previously reported at $80 \%$, likely impacts the accuracy of diagnosis. [37] The initial learning curve can affect inter-observer disagreement and prior work demonstrates rapid improvement in the first 40 cases. [38] In the hope of reducing inter-observer variability and simplifying assessment, PIRADs version 2.1 was introduced which maintained the majority framework of version 2 while incorporating some minor adjustments.[16] Critical changes focused on transition zone interpretation including upgrading of PIRADS 2 lesions to PIRADS 3 based on DWI scores. Given the low cancer detection rate of PIRADS 2 and PIRADS 3 lesions and the limited evidence to support it, adoption of PIRADs version 2.1 has been variable and the changes remain controversial. Five radiologist read a 355 patients cohort to concrete this concept that version 2.1 has better inter-observer agreement, especially in transitional zone. [39] 



\section{Clinical Utility of Multiparametric MRI in Prostate Cancer Diagnosis}

The introduction of $\mathrm{mpMRI}$ and its evolving indications have transformed the diagnostic paradigm for prostate cancer. The growing body of evidence supporting its use has facilitated its inclusion in guidelines supporting its increased use and influencing coverage decisions to ensure reimbursement. Following MRI, targeted biopsy (TBx) can be directly biopsied under MRI guidance (in-bore MRI TBx), with software-based fusion biopsy platforms, or visual registration/cognitive fusion biopsy. [40] One-stop MRI TBx was also feasible for patient to receive TBx right after the mpMRI was performed which shows not inferior to traditional TBx at the second visit and provides shorter diagnosis time. [41] Table 1. summarizes selected studies verifying the role of mpMRI and its accuracy in different clinical scenarios in recent years.

\section{Biopsy naïve population}

Prostate ultrasound has limited discriminative value for benign and malignant lesions. Additionally, given its random nature, sampling is not directed to areas of highest yield for clinically significant disease. PSA-detected indolent PCa captured by SBx had no survival benefit with treatment in the ProtecT trial at 10 years followup.[3] Given the poor specificity of PSA alone, men are unnecessarily exposed to the risks of biopsy including infectious hospitalizations/sepsis(1-4\%), hematuria, hematochezia, lower urinary tract symptoms, and urinary retention, amongst others. [42] At the same time, a considerable proportion of significant PCa is overlooked. The ability to better identify a priori which men should undergo biopsy to detect significant PCa, and ensure that biopsy will provide the most accurate and useful result is improved by the $\mathrm{mpMRI}$.

A systematic review assessing the diagnostic accuracy of mpMRI showed sensitivities of $58-96 \%$, specificities of $23-87 \%$, and negative predictive value of $63-98 \%$.[10] And a more recent review showed $\mathrm{mpMRI}$ had a pooled sensitivity of $91 \%$ with a pooled specificity 37\%.[43] Although results were overall promising, the wide ranges reflect study limitations including single-center series and retrospective design. The Prostate MR Imaging Study (PROMIS), was a prospective paired validation cohort study that aimed determine whether mpMRI before biopsy can be beneficial to patients.[44] This study used transperineal template mapping biopsy as the reference standard, of which technique reported to have the negative predictive value (NPV) of mpMRI for PCa was $92 \%$; and the NPV for csPCa was $89 \%$ for Gleason score $\geq 4+3$ /any cancer core length $\geq 6 \mathrm{~mm}$ and $72 \%$ for Gleason score $\geq 3+4$ / any cancer core length $\geq 4 \mathrm{~mm}$. $[45,46]$ This PROMIS study proposed diagnostic pathway with mpMRI pre- 
biopsy could avoid biopsy in $27 \%$ of patients while identifying $17 \%$ more clinically significant cancers if only those with MR-visible lesions required biopsy. [37] Fusion biopsy has been shown to add diagnostic value compared to conventional TRUS biopsies alone in meta-analysis and further supported by more recent single institution, prospective studies.[47-49] The PRECISION trial was a multi-national trial randomizing 500 biopsy-naïve patients into two groups: mpMRI with or without TBx alone versus standard TRUS biopsy. [50] The primary endpoint of the trial was to compare the proportion of csPCa, grade group $(\mathrm{GG}) \geq 2$, detected by both diagnostic pathways. It ultimately demonstrated that mpMRI and TBx was superior to TRUS biopsy, with the csPCa detection rate being $36 \%$ and $26 \%$ in $\mathrm{mpMRI}$ and standard pathway, respectively. Consistent with prior studies, detection of clinically insignificant PCa was lower in the mpMRI group. Given that men with a negative mpMRI did not undergo biopsy, the NPV was not determined.

The primary endpoint of a recent prospective, multicenter, and paired diagnostic study (MRI-FIRST trial), in men undergoing SBx alone if mpMRI was negative or SBx and TBx if a lesion noted, was detection of $\geq G G 2$.[51] SBx alone identified $30 \%$ of significant cancers, while TBx alone found $32 \%$. There was no difference in detection of clinically significant cancer between the groups, highlighting the need to both systematic and targeted sampling.

The PRECISION and PROMIS trials reported about that a quarter of patients, $28 \%$ and $27 \%$ respectively could potentially avoid biopsy completely. van der Leest et al. reported the avoidance rate was almost half, $49 \%$; and for those patients without a suspicious lesion on $\mathrm{MRI}, 3 \%$ harbored csPCa at immediate biopsy, increasing only to $4 \%$ at 1 year follow-up.[52,37] This was a head-to-head prospective multicenter trial using $\mathrm{GG} \geq 2$ in any core as csPCa and double expert consensus reading which minimizing the PI-RADS 3 diagnosis (6\%) which was notable less prevalent than prior studies (22\%-32\%).[53] Moreover, the clinically insignificant PCa detected rate was reported to be $14 \%$ and $23 \%$ in MRI and TRUS biopsy pathway respectively.[52]

MRI has been studied as a triage tool to aid in selection of men who would benefit the most for biopsy. Immediate biopsies can be selectively avoided in patients with negative mpMRI study and favorable PSA values/density.[54] While the identification of targets for sampling has improved the diagnosis of csPCa, there appears to be a continued role for systematic sampling. The optimal screening MR protocol and costeffectiveness require further study. 


\section{Repeat biopsy setting}

Prostate MRI initially established its role in men with a prior negative biopsy and continued suspicion for occult disease. $[47,48,55]$ Historically, a high proportion (60$75 \%$ ) of 'blind' biopsies in men with elevated PSA/abnormal DRE resulted in benign pathology $[56,57]$ A false negative on SBx may lead to delay in treatment and often requires additional biopsies with additional core sampling to achieve an accurate diagnosis.[58]

MpMRI with fusion biopsy can identify areas outside of the conventional template (anterior, midline, distal apex). The PICTURE trial [59], a paired-cohort validating confirmatory study, examined patients requiring repeat biopsy using transperineal template mapping biopsies as reference standard. It showed that the most patient with negative MRI can avoid immediately biopsy according to its high NPV, 91\% in Likert score $\geq 3$ and $83 \%$ in Likert score $\geq 4$ group respectively. Another multiinstitutional review concretes this concept with a result that all TBX are more accurate than standard biopsies despite the numbers of prior negative biopsy results.[55] The consensus statement by American Urological Association and Society of Abdominal Radiology also advised the patient warrant repeat biopsy when MRI detected PIRADS 3-5 lesions and at least two cores should be sampled at each lesion.[60]

\section{Utility of MRI in Active surveillance}

Active surveillance (AS) should be the standard of care in low and very-low risk PCa. It has been widely adopted as maturing data of long-term AS series and the ProtecT trial have demonstrated favorable outcomes.[3] Despite this, a number of men and physicians still elect for definitive treatment due to ongoing patient and physician uncertainty regarding patient's disease status. Historical tools for risk stratification (PSA, DRE, and Gleason score) have been insufficient although, recently serum, tissue, and imaging-based biomarkers have shown significant promise. The concept of MRI as a confirmatory test during the consideration phase of AS was introduced to gain additional information into disease risk prior to selecting a management strategy or initiation of AS.[61] Using MRI based scoring system, prostate cancer radiological estimation of change in sequential evaluation (PRECISE) for example, showed the evidence to reduce the disqualified rate compared with 12-core based AS candidate.[62] MRI can help identify suspicious lesions that can be targeted during confirmatory biopsy. $[63,48]$ Though MRI is imperfect, it has been shown with alternative confirmatory tests to reduce the incidence of adverse pathology in men who proceed to radical prostatectomy.[64] 
The ASIST trial randomized 273 men to either confirmatory SBx alone, or MRI with systematic and TBx in men initially diagnosed with GG1 PCa. TBx did not demonstrate a significantly higher upgrading risk than SBx, however, each modality identified unique cases of upgrading, highlighting the value of both systematic and TBx information. [65] Additionally there were differences in TBx cancer detection rates between sites despite centralized MRI interpretation, potentially underscoring differences in experience or technique with fusion biopsy. Importantly, at 2-year follow-up there was a $50 \%$ reduction of AS failure in the MRI pathway, demonstrating a role for better long-term risk stratification.[66]

Incorporation of mpMRI for decision making seems reasonable to avoid unnecessary and frequent protocol biopsies due to reported high NPV.[60] Further studies for implementing $\mathrm{mpMRI}$ into current protocol for AS are still required.

\section{Utility of MRI in target focal therapy}

The morbidity of definitive treatment is a legitimate concern given the historical propensity of overdiagnosis and overtreatment of indolent cancers. Approximately half of patients are eligible candidates for focal therapy (FT). [67] As evidence demonstrates limited benefit from definitive treatment of favorable-risk prostate cancers, FT has become an appealing alternative. [68]

FT can ablate defined volumes of cancer while minimizing the collateral damage to vital structures, e.g. sphincter, bladder neck, and neurovascular bundle, and better preserve functional outcomes. [69] MRI with TBx help clinicians localize the lesion and accurately define the focal ablative volume to be treated. [70,71] $\mathrm{MRI}$ is also critical in post FT follow-up, where the DCE sequence becomes the dominant sequence although the number of studies is few. [72]

FT has achieved good short-term outcomes but still lacks long-term evidence, is composed of relatively small cohorts and lack comparative treatment outcomes. [73] Further high level trials providing evidence of outcomes and patient selection is requisite before FT becoming widely adopted.

\section{Utility of MRI in pre-prostatectomy}

MRI has adequate spatial resolution to characterize most prostate cancer location, size, adverse features. [74] The surgeon can use this information to stratify risk of extracapsular, plan bladder neck dissection and margins/nerve-sparing. A randomized control trail showed the benefit of reducing the positive margin rate in 
CT1 cases only. [75] Further meta-analysis reported the surgical positive rate dose not associate with the MRI although surgeons still planning the neurovascular bundle depend on the image finding. [76] However, the MRI features such as tumor size and PIRADS score has additional value to predict post-prostatectomy biochemical recurrence which can provide further information to support clinical decision-making in intermediate and high-risk disease. [77] 


\section{Use of MRI in post-treatment follow-up}

A number of options are available for the management of localized PCa including radical prostatectomy and radiation (EBRT and brachytherapy) in selected patients. Despite early diagnosis and treatment, biochemical recurrence can occur in up to 40\%.[78] MRI can characterize locally recurrent disease after both surgery or radiation therapy and help guide salvage treatment options.

The acquisition and reporting system, including both anatomic and functional data, of mpMRI, is similar to PI-RADS version 2.[33] Although using similar sequences in the post-treatment setting, the anatomic changes after surgery, radiation and ablation represent unique challenges. Therefore, the functional information provided by dynamic contrast enhanced MRI and DWI, play a greater role in this setting. Some studies suggest that a complete mpMRI with endorectal coil, acquired at $3 T$ with contrast injection, may help improve sensitivity and specificity.[79,80] While DWI can be useful for the differentiation between inflammation and post focal therapy or radiotherapy residual benign prostatic tissue from malignancy, image interpretation can be affected by artifacts generated from metal clips in the post-operative setting. [81] Additionally, perfusion characteristics on DCE MRI can provide diagnostic value especially in the post-radiation or ablation setting.[82]

Overall, recurrent tumors display similar characteristics to tumors diagnosed in the primary setting. However, the changes in post-treatment tissue that may mimic residual disease can be informed by clinical history and PSA kinetics. 


\section{Conclusions}

Since its introduction into the diagnostic pathway, mpMRI and targeted biopsy have shown value in multiple clinical settings. Use of pre-biopsy mpMRI has the advantage of limiting the diagnosis of small volume, low risk cancers while simultaneously increasing the sensitivity to detect clinically significant prostate cancer. Currently, the combination of both systematic and targeted biopsies improves the diagnostic accuracy. As rapid adoption increase, a focus on quality assurance is imperative to ensure that similar outcomes are achieved outside of expert academic centers.

Conflicts of interest

Boris A. Hadaschik reports personal fees from ABX, Bayer, Lightpoint Medical, Inc., Janssen R\&D, Bristol-Myers-Squibb and Astellas and travel from AstraZeneca, Janssen R\&D and Astellas.

Acknowlegement

Mark Emberton receives research support from the United Kingdom's National Institute of Health Research (NIHR) UCLH / UCL Biomedical Research Centre. 


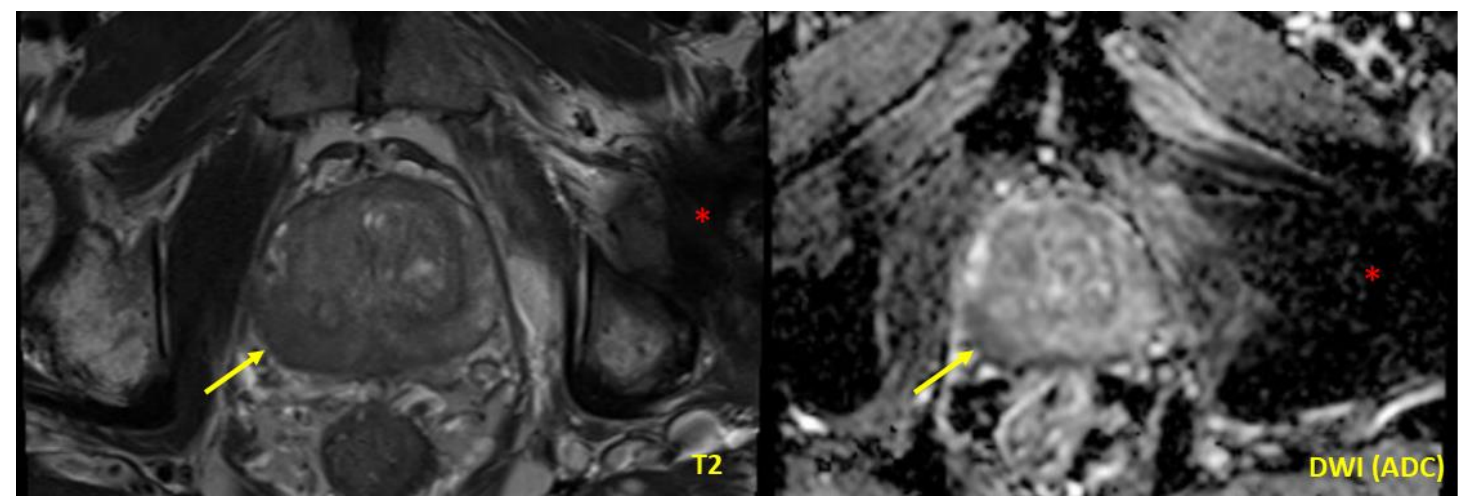

Figure 1. Granulomatous prostatitis mimicking high grade prostate cancer may manifest as a PIRADS 5 lesion on MRI. The arrow denotes a $2.2 \mathrm{~cm}$ diffuse area of low signal intensity at the right mid peripheral zone that corresponds to restricted diffusion on the ADC map. The star denotes image artefact introduced by a left hip prosthesis. Despite the presence of a prosthesis, the images are diagnostic and can still provide important information for detection and staging.

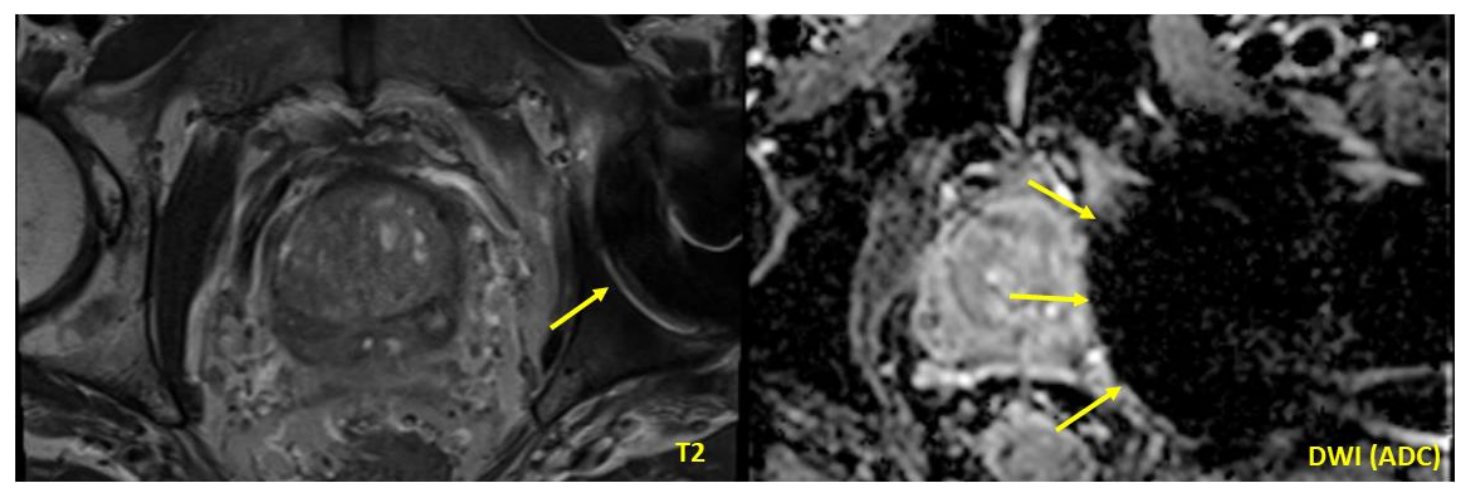

Figure 2. Imaging artefact introduced by the presence of a left hip prosthesis. On T2 weighted imaging the distortion does not obscure the prostate image, however on diffusion weighted imaging the prosthesis renders interpretation of the left lateral aspect of the prostate non-diagnostic.

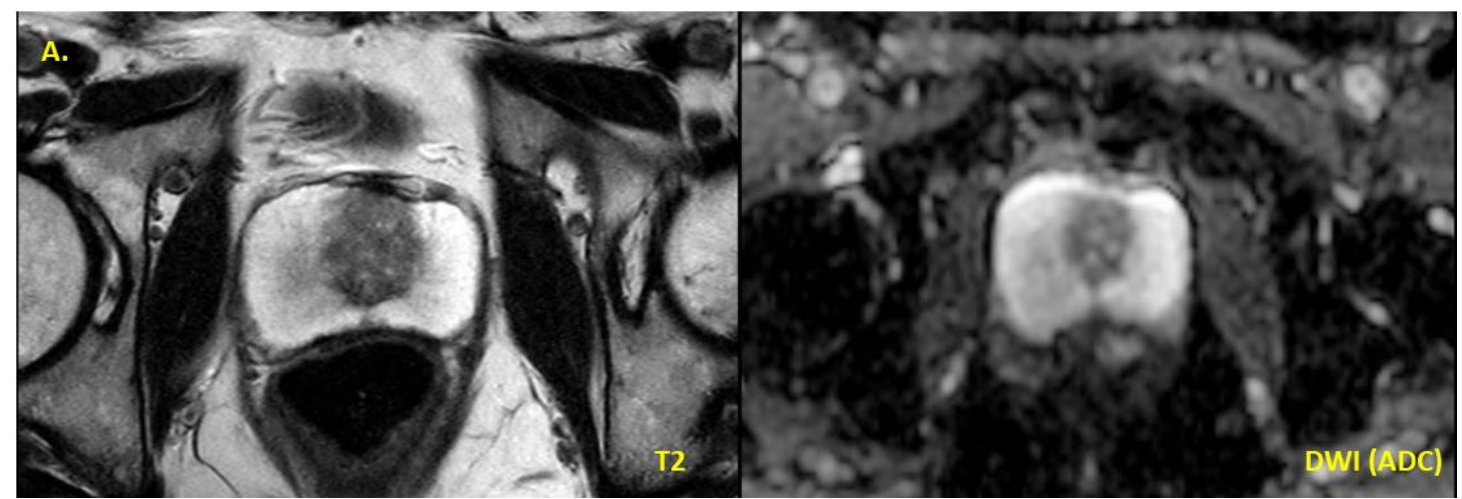



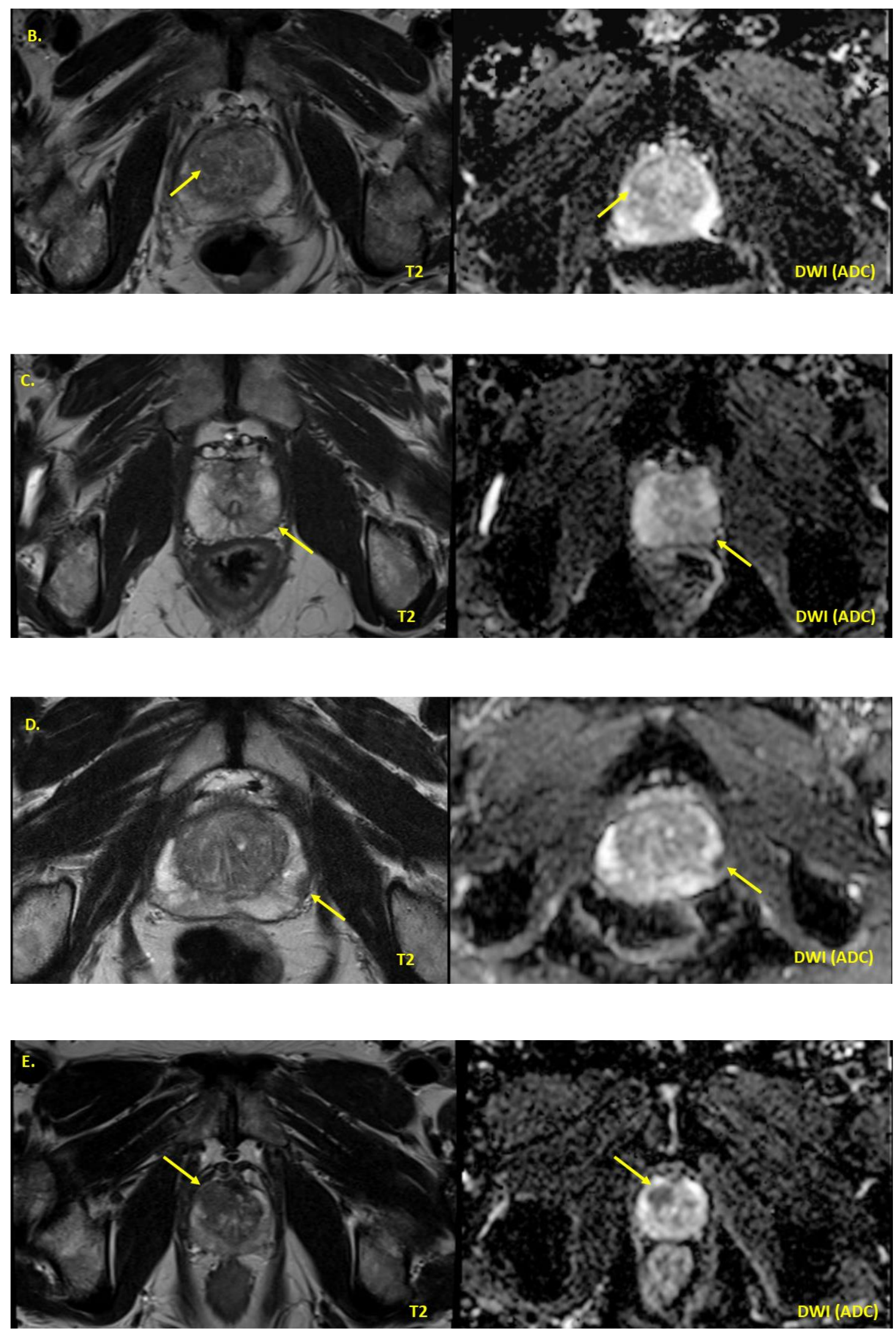
Figure 3. PIRADS V2.1 provides standardization of image interpretation of multiparametric Prostate MRI. A) T2-weighted and ADC map of PIRADS 1 demonstrating a peripheral and transition zone without evidence of low signal intensity or restricted diffusion. B) PIRADS 2 lesion of the right anterior transition zone. T2-weighted imaging demonstrates low signal intensity within a wellcircumscribed nodule consistent with $\mathrm{BPH}$ and $\mathrm{ADC}$ map demonstrates mildly restricted diffusion. C) PIRADS 3 finding consistent with prostatitis. Regional/diffuse low signal intensity of the left mid peripheral zone which corresponds to mildly restricted diffusion. D) PIRADS 4 lesion of the Left mid posterior lateral peripheral zone. There is an $8 \mathrm{~mm}$ region of low signal intensity and corresponding restricted diffusion. E) PIRADS 5 lesion of the right apical anterior transition zone. The lesion demonstrates a classic "erased charcoal" appearance with indistinct border. The $1.7 \mathrm{~cm}$ lesion exhibits capsular bulge concerning for extracapsular extension and corresponds to severely restricted diffusion on the ADC map. 



\begin{tabular}{|c|c|c|c|c|}
\hline Study & $\begin{array}{l}\text { Level of } \\
\text { evidence }\end{array}$ & $\begin{array}{c}\text { Case } \\
\text { number }\end{array}$ & Finding & $\begin{array}{l}\text { Definition of significant } \\
\text { Prostate Cancer }\end{array}$ \\
\hline \multicolumn{5}{|c|}{ Biopsy naïve } \\
\hline $\begin{array}{l}\text { Kasivisvanathan et al. } \\
\text { (PRECISION) [50] }\end{array}$ & $\begin{array}{l}1 \mathrm{~b} \\
\text { Multicenter } \\
\text { Randomized } \\
\text { Noninferiority } \\
\text { trail }\end{array}$ & 500 & $\begin{array}{l}\text { PIRADS csPCa vs insignificant } \\
3: 12 \% \text { vs } 22 \% \\
4: 60 \% \text { vs } 9 \% \\
5: 83 \% \text { vs } 11 \% \\
\text { TBx is superior to SBx }\end{array}$ & $\mathrm{GG} \geq 2$ \\
\hline Ahmed et al. (PROMIS) & $1 b$ & 576 & $\begin{array}{l}\text { Inter-observer agreement } 80 \% \\
\text { Sens: } 93 \%, \text { Spec: } 41 \% \\
\text { PPV: } 51 \%, \text { NPV: } 89 \% \\
\text { Patient can avoid biopsy safely if MRI was negative }\end{array}$ & $\begin{array}{l}\text { Likert score } \\
G G \geq 3 \\
\text { (there are two other } \\
\text { definitions) }\end{array}$ \\
\hline $\begin{array}{l}\text { Rouviere et al. } \\
\text { (MRI-FIRST) [51] }\end{array}$ & $\begin{array}{l}1 \mathrm{~b} \\
16 \text { France } \\
\text { centers } \\
\text { prospective, } \\
\text { multicenter, } \\
\text { paired diagnostic } \\
\text { study }\end{array}$ & 251 & $\begin{array}{l}\text { no difference between SBx and TBx in csPCa ( } 29.9 \% \text { vs } 32.3 \%) \text {. Improve } \\
\text { after combination. MRI before biopsy is helpful but SBx is still essential. }\end{array}$ & $\begin{array}{l}\text { Likert score } \\
G G \geq 2\end{array}$ \\
\hline Porpiglia et al.[49] & $1 b$ & 212 & $\begin{array}{l}\text { Both cancer and csPCa detection rate of TBx is better than SBx: PCa } \\
(50.5 \% \text { vs } 29.5 \% \text {, respectively; } p=0.002) \text { and csPCa }(43.9 \% \text { vs } 18.1 \% \text {, } \\
\text { respectively; } p<0.001) \text {. }\end{array}$ & $\begin{array}{l}\text { (biopsy } \mathrm{GG} \geq 3 \text { or } \\
\text { maximum } C C L \geq 5 \mathrm{~mm}\end{array}$ \\
\hline
\end{tabular}




\begin{tabular}{|c|c|c|c|c|}
\hline van der Leest et al. [52] & 2 & 626 & $\begin{array}{l}\text { Biopsy performed in-bore. csPCa } 23 \% \text { of TRUS biopsy and } 25 \% \text { of MRI } \\
\text { guided biopsy. Biopsy in PIRADS 1-2 MRI found 3\% (10/309) csPCa. }\end{array}$ & $G G \geq 2$ \\
\hline \multicolumn{5}{|c|}{ Prior negative/ Repeat biopsies } \\
\hline $\begin{array}{l}\text { Simmons et al. } \\
\text { (PICTURE) [59] }\end{array}$ & $\begin{array}{l}1 \mathrm{~b} \\
\text { prospective } \\
\text { diagnostic } \\
\text { validating cohort }\end{array}$ & 249 & $\begin{array}{l}\text { Repeat biopsy can be avoided by mpMRI. But still some csPCa may be } \\
\text { missed }\end{array}$ & $\begin{array}{l}\text { Likert } \\
\text { GSG } \geq 3 \\
\text { Cancer core length } \geq 6 \mathrm{~mm}\end{array}$ \\
\hline $\begin{array}{l}\text { Wegelin et al. } \\
\text { (FUTURE) [83] }\end{array}$ & $\begin{array}{l}1 \mathrm{~b} ? \\
\text { Multicenter } \\
\text { randomized } \\
\text { controlled trial }\end{array}$ & 665 & $\begin{array}{l}\text { The additional value of SBx was limited, and only } 1.3 \% \text { of csPCa would } \\
\text { have been missed when SBx had been omitted }\end{array}$ & $G G \geq 2$ \\
\hline Sidana et al. [55] & 2 & 779 & $\begin{array}{l}\text { Total csPCa was } 30.7 \% \text { and TBx csPCa was } 26.3 \% \text {. } \\
\text { TBx is outperforming SBx in prior negative patient. }\end{array}$ & $\mathrm{GG} \geq 2$ \\
\hline $\begin{array}{l}\text { Truong et al. [84] } \\
\text { (aim for benign lesion) }\end{array}$ & 2 & 285 & In prior negative patients, false positive MRI may occur in up to $46.3 \%$. & $G G \geq 2$ \\
\hline \multicolumn{5}{|c|}{ Active surveillance } \\
\hline Klotz et al. (ASIST) [65] & $\begin{array}{l}\text { 1b } \\
\text { prospective } \\
\text { randomized } \\
\text { multicenter } \\
\text { open-label }\end{array}$ & 273 & $\begin{array}{l}\text { No difference in upgrading rate. } \\
\text { Both TBx and SBx missed } 8 \% \text { and } 6 \% \text { csPCa. } \\
\text { In the most experience sites, TBx is superior to SBx. }\end{array}$ & $G G \geq 2$ \\
\hline Tran et al. [85] & 2 & 207 & $40 \%$ experienced any upgrading, including $24 \%$ on systematic sampling, & Upgrading: GG2 \\
\hline
\end{tabular}




\begin{tabular}{|c|c|c|c|c|}
\hline & & & $\begin{array}{l}14 \% \text { on MRI-targeted cores, and } 2 \% \text { on both. } \\
\text { upgrading also occurred in areas outside TBx, suggesting that systematic } \\
\text { sampling should be offered to men with AS }\end{array}$ & Major upgrading: GG3 \\
\hline Jayadevan et al[86] & 2 & 332 & $\begin{array}{l}\text { Confirmatory biopsy with MRI guidance is significantly associated with } \\
\text { future disease upgrading of prostate cancer, especially when combined } \\
\text { with PSA density. } \\
\text { Upgrade to at least GG3 rate } 7.9 \% \text { vs } 11.4 \text { vs } 23.3 \% \text { in confirmatory } \\
\text { normal, GG1 and GG2, respectively. }\end{array}$ & $\begin{array}{l}\text { Upgrading } \\
\text { GG3 }\end{array}$ \\
\hline Frye et al. [87] & 2 & 166 & $\begin{array}{l}\text { TBx alone identified } 44.9 \% \text { of patients who progressed compared to } \\
30.6 \% \text { identified by systematic } 12 \text {-core biopsy alone } \\
81 \% \text { NPV in detecting pathological progression } \\
\text { Multiparametric magnetic resonance imaging progression predicts the } \\
\text { risk of pathological progression. }\end{array}$ & $\begin{array}{l}\text { Upgrading } \\
\text { GG } 1 \text { to } 2 \\
\text { Or GG } 2 \text { to } 3\end{array}$ \\
\hline \multicolumn{5}{|c|}{ Miscellaneous } \\
\hline Siddiqui et al. [48] & 2 & 1003 & $\begin{array}{l}\text { TBx diagnosed } 30 \% \text { more high-risk cancers vs SBx ( } 173 \text { vs } 122 \text { cases, } P \\
<.001 \text { ) and } 17 \% \text { fewer low-risk cancers ( } 213 \text { vs } 258 \text { cases, } P<.001 \text { ). }\end{array}$ & $\begin{array}{l}\text { High volume } G G 2 \text { and } \\
\geq G G 3\end{array}$ \\
\hline Ahdoot et al. [91] & 2 & 2103 & $\begin{array}{l}\text { TBx alone found } 12.7 \% \geq \mathrm{GG} 2 \text { cancers vs } \mathrm{SBx}(5.8 \%) \\
\text { TBx found } 3.5 \% \text { new } \mathrm{GG} 1 \text { cancers vs } \mathrm{SBx}(7.8 \%) \\
\text { Combined TBx and } \mathrm{SBx} \text { can provider more accurate diagnosis which is } \\
9.9 \% \text { more than either technique alone. }\end{array}$ & GG2 \\
\hline
\end{tabular}

Table 1. Studies of mpMRI with or without targeted biopsy for detection prostate cancer. csPCa: clinically significant prostate cancer; GG: grade group; TBx: targeted biopsy; SBx: systematic biopsy. 



\section{References}

1. Bray F, Ferlay J, Soerjomataram I, Siegel RL, Torre LA, Jemal A (2018) Global cancer statistics 2018: GLOBOCAN estimates of incidence and mortality worldwide for 36 cancers in 185 countries. CA Cancer J Clin 68 (6):394-424. doi:10.3322/caac.21492 2. McNeal JE, Bostwick DG, Kindrachuk RA, Redwine EA, Freiha FS, Stamey TA (1986) Patterns of progression in prostate cancer. Lancet 1 (8472):60-63. doi:10.1016/s01406736(86)90715-4

3. Hamdy FC, Donovan JL, Lane JA, Mason M, Metcalfe C, Holding P, Davis M, Peters TJ, Turner EL, Martin RM, Oxley J, Robinson M, Staffurth J, Walsh E, Bollina P, Catto J, Doble A, Doherty A, Gillatt D, Kockelbergh R, Kynaston H, Paul A, Powell P, Prescott S, Rosario DJ, Rowe E, Neal DE, Protec TSG (2016) 10-Year Outcomes after Monitoring, Surgery, or Radiotherapy for Localized Prostate Cancer. N Engl J Med 375 (15):14151424. doi:10.1056/NEJMoa1606220

4. Force USPST, Grossman DC, Curry SJ, Owens DK, Bibbins-Domingo K, Caughey AB, Davidson KW, Doubeni CA, Ebell M, Epling JW, Jr., Kemper AR, Krist AH, Kubik M, Landefeld CS, Mangione CM, Silverstein M, Simon MA, Siu AL, Tseng CW (2018) Screening for Prostate Cancer: US Preventive Services Task Force Recommendation Statement. JAMA 319 (18):1901-1913. doi:10.1001/jama.2018.3710

5. Engelbrecht MR, Barentsz JO, Jager GJ, van der Graaf M, Heerschap A, Sedelaar JP, Aarnink RG, de la Rosette JJ (2000) Prostate cancer staging using imaging. BJU Int 86 Suppl 1:123-134. doi:10.1046/j.1464-410x.2000.00592.x

6. Guichard G, Larre S, Gallina A, Lazar A, Faucon H, Chemama S, Allory Y, Patard JJ, Vordos D, Hoznek A, Yiou R, Salomon L, Abbou CC, de la Taille A (2007) Extended 21sample needle biopsy protocol for diagnosis of prostate cancer in 1000 consecutive patients. Eur Urol 52 (2):430-435. doi:10.1016/j.eururo.2007.02.062

7. Hoeks CM, Barentsz JO, Hambrock T, Yakar D, Somford DM, Heijmink SW, Scheenen TW, Vos PC, Huisman H, van Oort IM, Witjes JA, Heerschap A, Futterer JJ (2011) Prostate cancer: multiparametric MR imaging for detection, localization, and staging. Radiology 261 (1):46-66. doi:10.1148/radiol.11091822

8. Vickers A, Carlsson SV, Cooperberg M (2020) Routine Use of Magnetic Resonance Imaging for Early Detection of Prostate Cancer Is Not Justified by the Clinical Trial Evidence. Eur Urol 78 (3):304-306. doi:10.1016/j.eururo.2020.04.016

9. Culp MB, Soerjomataram I, Efstathiou JA, Bray F, Jemal A (2019) Recent Global Patterns in Prostate Cancer Incidence and Mortality Rates. Eur Urol. doi:10.1016/j.eururo.2019.08.005 10. Futterer JJ, Briganti A, De Visschere P, Emberton M, Giannarini G, Kirkham A, Taneja SS, Thoeny H, Villeirs G, Villers A (2015) Can Clinically Significant Prostate 
Cancer Be Detected with Multiparametric Magnetic Resonance Imaging? A Systematic Review of the Literature. Eur Urol 68 (6):1045-1053.

doi:10.1016/j.eururo.2015.01.013

11. Cabarrus MC, Westphalen AC (2017) Multiparametric magnetic resonance imaging of the prostate-a basic tutorial. Transl Androl Urol 6 (3):376-386. doi:10.21037/tau.2017.01.06

12. Ullrich T, Quentin M, Oelers C, Dietzel F, Sawicki LM, Arsov C, Rabenalt R, Albers $P$, Antoch G, Blondin D, Wittsack HJ, Schimmoller L (2017) Magnetic resonance imaging of the prostate at 1.5 versus 3.0T: A prospective comparison study of image quality. Eur J Radiol 90:192-197. doi:10.1016/j.ejrad.2017.02.044

13. Margolis DJ (2014) Multiparametric MRI for localized prostate cancer: lesion detection and staging. Biomed Res Int 2014:684127. doi:10.1155/2014/684127 14. Gawlitza J, Reiss-Zimmermann M, Thormer G, Schaudinn A, Linder N, Garnov N, Horn LC, Minh DH, Ganzer R, Stolzenburg JU, Kahn T, Moche M, Busse H (2017) Impact of the use of an endorectal coil for $3 \mathrm{~T}$ prostate MRI on image quality and cancer detection rate. Sci Rep 7:40640. doi:10.1038/srep40640

15. Shah ZK, Elias SN, Abaza R, Zynger DL, DeRenne LA, Knopp MV, Guo B, Schurr R, Heymsfield SB, Jia G (2015) Performance comparison of 1.5-T endorectal coil MRI with 3.0-T nonendorectal coil MRI in patients with prostate cancer. Acad Radiol 22 (4):467-474. doi:10.1016/j.acra.2014.11.007

16. Turkbey B, Rosenkrantz AB, Haider MA, Padhani AR, Villeirs G, Macura KJ, Tempany CM, Choyke PL, Cornud F, Margolis DJ, Thoeny HC, Verma S, Barentsz J, Weinreb JC (2019) Prostate Imaging Reporting and Data System Version 2.1: 2019 Update of Prostate Imaging Reporting and Data System Version 2. Eur Urol 76 (3):340-351. doi:10.1016/j.eururo.2019.02.033

17. Kumar V, Bora GS, Kumar R, Jagannathan NR (2018) Multiparametric (mp) MRI of prostate cancer. Prog Nucl Magn Reson Spectrosc 105:23-40.

doi:10.1016/j.pnmrs.2018.01.001

18. White S, Hricak H, Forstner R, Kurhanewicz J, Vigneron DB, Zaloudek CJ, Weiss JM, Narayan P, Carroll PR (1995) Prostate cancer: effect of postbiopsy hemorrhage on interpretation of MR images. Radiology 195 (2):385-390.

doi:10.1148/radiology.195.2.7724756

19. Mussi TC, Baroni RH, Zagoria RJ, Westphalen AC (2019) Prostate magnetic resonance imaging technique. Abdom Radiol (NY). doi:10.1007/s00261-019-02308-5 20. Futterer JJ (2017) Multiparametric MRI in the Detection of Clinically Significant Prostate Cancer. Korean J Radiol 18 (4):597-606. doi:10.3348/kjr.2017.18.4.597

21. Hricak H (1999) Imaging prostate cancer. J Urol 162 (4):1329-1330.

doi:10.1016/s0022-5347(05)68278-x 
22. Metens T, Miranda D, Absil J, Matos C (2012) What is the optimal b value in diffusion-weighted MR imaging to depict prostate cancer at 3T? Eur Radiol 22 (3):703-709. doi:10.1007/s00330-011-2298-9

23. Wang X, Qian Y, Liu B, Cao L, Fan Y, Zhang JJ, Yu Y (2014) High-b-value diffusionweighted MRI for the detection of prostate cancer at 3 T. Clin Radiol 69 (11):11651170. doi:10.1016/j.crad.2014.07.013

24. Hambrock T, Somford DM, Huisman HJ, van Oort IM, Witjes JA, Hulsbergen-van de Kaa CA, Scheenen T, Barentsz JO (2011) Relationship between apparent diffusion coefficients at 3.0-T MR imaging and Gleason grade in peripheral zone prostate cancer. Radiology 259 (2):453-461. doi:10.1148/radiol.11091409

25. Verma S, Turkbey B, Muradyan N, Rajesh A, Cornud F, Haider MA, Choyke PL, Harisinghani $M$ (2012) Overview of dynamic contrast-enhanced MRI in prostate cancer diagnosis and management. AJR Am J Roentgenol 198 (6):1277-1288. doi:10.2214/AJR.12.8510

26. Rais-Bahrami S, Siddiqui MM, Vourganti S, Turkbey B, Rastinehad AR, Stamatakis L, Truong H, Walton-Diaz A, Hoang AN, Nix JW, Merino MJ, Wood BJ, Simon RM, Choyke PL, Pinto PA (2015) Diagnostic value of biparametric magnetic resonance imaging (MRI) as an adjunct to prostate-specific antigen (PSA)-based detection of prostate cancer in men without prior biopsies. BJU Int 115 (3):381-388.

doi:10.1111/bju.12639

27. Kuhl CK, Bruhn R, Kramer N, Nebelung S, Heidenreich A, Schrading S (2017) Abbreviated Biparametric Prostate MR Imaging in Men with Elevated Prostatespecific Antigen. Radiology 285 (2):493-505. doi:10.1148/radiol.2017170129 28. Dickinson L, Ahmed HU, Allen C, Barentsz JO, Carey B, Futterer JJ, Heijmink SW, Hoskin P, Kirkham AP, Padhani AR, Persad R, Puech P, Punwani S, Sohaib A, Tombal B, Villers A, Emberton M (2013) Scoring systems used for the interpretation and reporting of multiparametric $\mathrm{MRI}$ for prostate cancer detection, localization, and characterization: could standardization lead to improved utilization of imaging within the diagnostic pathway? J Magn Reson Imaging 37 (1):48-58. doi:10.1002/jmri.23689 29. Barentsz JO, Richenberg J, Clements R, Choyke P, Verma S, Villeirs G, Rouviere O, Logager V, Futterer JJ, European Society of Urogenital R (2012) ESUR prostate MR guidelines 2012. Eur Radiol 22 (4):746-757. doi:10.1007/s00330-011-2377-y 30. Hamoen EHJ, de Rooij M, Witjes JA, Barentsz JO, Rovers MM (2015) Use of the Prostate Imaging Reporting and Data System (PI-RADS) for Prostate Cancer Detection with Multiparametric Magnetic Resonance Imaging: A Diagnostic Meta-analysis. Eur Urol 67 (6):1112-1121. doi:10.1016/j.eururo.2014.10.033

31. Abd-Alazeez M, Ahmed HU, Arya M, Allen C, Dikaios N, Freeman A, Emberton M, Kirkham A (2014) Can multiparametric magnetic resonance imaging predict 
upgrading of transrectal ultrasound biopsy results at more definitive histology? Urol Oncol 32 (6):741-747. doi:10.1016/j.urolonc.2014.01.008

32. Rosenkrantz AB, Kim S, Lim RP, Hindman N, Deng FM, Babb JS, Taneja SS (2013)

Prostate cancer localization using multiparametric MR imaging: comparison of Prostate Imaging Reporting and Data System (PI-RADS) and Likert scales. Radiology 269 (2):482-492. doi:10.1148/radiol.13122233

33. Weinreb JC, Barentsz JO, Choyke PL, Cornud F, Haider MA, Macura KJ, Margolis D, Schnall MD, Shtern F, Tempany CM, Thoeny HC, Verma S (2016) PI-RADS Prostate Imaging - Reporting and Data System: 2015, Version 2. Eur Urol 69 (1):16-40. doi:10.1016/j.eururo.2015.08.052

34. Hansford BG, Peng Y, Jiang Y, Vannier MW, Antic T, Thomas S, McCann S, Oto A (2015) Dynamic Contrast-enhanced MR Imaging Curve-type Analysis: Is It Helpful in the Differentiation of Prostate Cancer from Healthy Peripheral Zone? Radiology 275 (2):448-457. doi:10.1148/radiol.14140847

35. Woo S, Suh CH, Kim SY, Cho JY, Kim SH (2017) Diagnostic Performance of Prostate Imaging Reporting and Data System Version 2 for Detection of Prostate Cancer: A Systematic Review and Diagnostic Meta-analysis. Eur Urol 72 (2):177-188. doi:10.1016/j.eururo.2017.01.042

36. Fascelli M, Rais-Bahrami S, Sankineni S, Brown AM, George AK, Ho R, Frye T, Kilchevsky A, Chelluri R, Abboud S, Siddiqui MM, Merino MJ, Wood BJ, Choyke PL, Pinto PA, Turkbey B (2016) Combined Biparametric Prostate Magnetic Resonance Imaging and Prostate-specific Antigen in the Detection of Prostate Cancer: A Validation Study in a Biopsy-naive Patient Population. Urology 88:125-134. doi:10.1016/j.urology.2015.09.035

37. Ahmed HU, El-Shater Bosaily A, Brown LC, Gabe R, Kaplan R, Parmar MK, CollacoMoraes Y, Ward K, Hindley RG, Freeman A, Kirkham AP, Oldroyd R, Parker C, Emberton M, group Ps (2017) Diagnostic accuracy of multi-parametric MRI and TRUS biopsy in prostate cancer (PROMIS): a paired validating confirmatory study. Lancet 389 (10071):815-822. doi:10.1016/S0140-6736(16)32401-1

38. Rosenkrantz AB, Ayoola A, Hoffman D, Khasgiwala A, Prabhu V, Smereka P, Somberg M, Taneja SS (2017) The Learning Curve in Prostate MRI Interpretation: SelfDirected Learning Versus Continual Reader Feedback. AJR Am J Roentgenol 208 (3):W92-W100. doi:10.2214/AJR.16.16876

39. Wei CG, Zhang YY, Pan P, Chen T, Yu HC, Dai GC, Tu J, Yang S, Zhao WL, Shen J (2020) Diagnostic Accuracy and Inter-observer Agreement of PI-RADS Version 2 and Version 2.1 for the Detection of Transition Zone Prostate Cancers. AJR Am J Roentgenol. doi:10.2214/AJR.20.23883

40. Venderink W, Bomers JG, Overduin CG, Padhani AR, de Lauw GR, Sedelaar MJ, 
Barentsz JO (2020) Multiparametric Magnetic Resonance Imaging for the Detection of Clinically Significant Prostate Cancer: What Urologists Need to Know. Part 3: Targeted Biopsy. Eur Urol 77 (4):481-490. doi:10.1016/j.eururo.2019.10.009 41. Tafuri A, Ashrafi AN, Palmer S, Shakir A, Cacciamani GE, Iwata A, Iwata T, Cai J, Sali A, Gupta C, Medina LG, Stern MC, Duddalwar V, Aron M, Gill IS, Abreu A (2020) OneStop MRI and MRI/transrectal ultrasound fusion-guided biopsy: an expedited pathway for prostate cancer diagnosis. World J Urol 38 (4):949-956. doi:10.1007/s00345-019-02835-2

42. Pepe $P$, Aragona F (2013) Morbidity after transperineal prostate biopsy in 3000 patients undergoing 12 vs 18 vs more than 24 needle cores. Urology 81 (6):11421146. doi:10.1016/j.urology.2013.02.019

43. Drost FH, Osses D, Nieboer D, Bangma CH, Steyerberg EW, Roobol MJ, Schoots IG (2020) Prostate Magnetic Resonance Imaging, with or Without Magnetic Resonance Imaging-targeted Biopsy, and Systematic Biopsy for Detecting Prostate Cancer: A Cochrane Systematic Review and Meta-analysis. Eur Urol 77 (1):78-94.

doi:10.1016/j.eururo.2019.06.023

44. El-Shater Bosaily A, Parker C, Brown LC, Gabe R, Hindley RG, Kaplan R, Emberton M, Ahmed HU, Group P (2015) PROMIS--Prostate MR imaging study: A paired validating cohort study evaluating the role of multi-parametric MRI in men with clinical suspicion of prostate cancer. Contemp Clin Trials 42:26-40. doi:10.1016/j.cct.2015.02.008 45. Ahmed HU, Hu Y, Carter T, Arumainayagam N, Lecornet E, Freeman A, Hawkes D, Barratt DC, Emberton M (2011) Characterizing clinically significant prostate cancer using template prostate mapping biopsy. J Urol 186 (2):458-464. doi:10.1016/j.juro.2011.03.147

46. Bittner N, Merrick GS, Bennett A, Butler WM, Andreini HJ, Taubenslag W, Adamovich E (2015) Diagnostic Performance of Initial Transperineal Template-guided Mapping Biopsy of the Prostate Gland. Am J Clin Oncol 38 (3):300-303. doi:10.1097/COC.0b013e31829a2954

47. Schoots IG, Roobol MJ, Nieboer D, Bangma CH, Steyerberg EW, Hunink MG (2015) Magnetic resonance imaging-targeted biopsy may enhance the diagnostic accuracy of significant prostate cancer detection compared to standard transrectal ultrasoundguided biopsy: a systematic review and meta-analysis. Eur Urol 68 (3):438-450. doi:10.1016/j.eururo.2014.11.037 48. Siddiqui MM, Rais-Bahrami S, Turkbey B, George AK, Rothwax J, Shakir N, Okoro C, Raskolnikov D, Parnes HL, Linehan WM, Merino MJ, Simon RM, Choyke PL, Wood BJ, Pinto PA (2015) Comparison of MR/ultrasound fusion-guided biopsy with ultrasound-guided biopsy for the diagnosis of prostate cancer. JAMA 313 (4):390-397. 
doi:10.1001/jama.2014.17942

49. Porpiglia F, Manfredi M, Mele F, Cossu M, Bollito E, Veltri A, Cirillo S, Regge D, Faletti R, Passera R, Fiori C, De Luca S (2017) Diagnostic Pathway with Multiparametric Magnetic Resonance Imaging Versus Standard Pathway: Results from a Randomized Prospective Study in Biopsy-naive Patients with Suspected Prostate Cancer. Eur Urol 72 (2):282-288. doi:10.1016/j.eururo.2016.08.041 50. Kasivisvanathan V, Rannikko AS, Borghi M, Panebianco V, Mynderse LA, Vaarala MH, Briganti A, Budaus L, Hellawell G, Hindley RG, Roobol MJ, Eggener S, Ghei M, Villers A, Bladou F, Villeirs GM, Virdi J, Boxler S, Robert G, Singh PB, Venderink W, Hadaschik BA, Ruffion A, Hu JC, Margolis D, Crouzet S, Klotz L, Taneja SS, Pinto P, Gill I, Allen C, Giganti F, Freeman A, Morris S, Punwani S, Williams NR, Brew-Graves C, Deeks J, Takwoingi Y, Emberton M, Moore CM, Collaborators PSG (2018) MRITargeted or Standard Biopsy for Prostate-Cancer Diagnosis. N Engl J Med 378 (19):1767-1777. doi:10.1056/NEJMoa1801993

51. Rouviere O, Puech P, Renard-Penna R, Claudon M, Roy C, Mege-Lechevallier F, Decaussin-Petrucci M, Dubreuil-Chambardel M, Magaud L, Remontet L, Ruffion A, Colombel M, Crouzet S, Schott AM, Lemaitre L, Rabilloud M, Grenier N, Investigators M-F (2019) Use of prostate systematic and targeted biopsy on the basis of multiparametric MRI in biopsy-naive patients (MRI-FIRST): a prospective, multicentre, paired diagnostic study. Lancet Oncol 20 (1):100-109. doi:10.1016/S1470-2045(18)30569-2

52. van der Leest $M$, Cornel E, Israel B, Hendriks R, Padhani AR, Hoogenboom M, Zamecnik P, Bakker D, Setiasti AY, Veltman J, van den Hout $H$, van der Lelij $H$, van Oort I, Klaver S, Debruyne F, Sedelaar M, Hannink G, Rovers M, Hulsbergen-van de Kaa C, Barentsz JO (2019) Head-to-head Comparison of Transrectal Ultrasound-guided Prostate Biopsy Versus Multiparametric Prostate Resonance Imaging with Subsequent Magnetic Resonance-guided Biopsy in Biopsy-naive Men with Elevated Prostate-specific Antigen: A Large Prospective Multicenter Clinical Study. Eur Urol 75 (4):570-578. doi:10.1016/j.eururo.2018.11.023

53. Schoots IG (2018) MRI in early prostate cancer detection: how to manage indeterminate or equivocal PI-RADS 3 lesions? Transl Androl Urol 7 (1):70-82. doi:10.21037/tau.2017.12.31

54. Watson MJ, George AK, Maruf M, Frye TP, Muthigi A, Kongnyuy M, Valayil SG, Pinto PA (2016) Risk stratification of prostate cancer: integrating multiparametric MRI, nomograms and biomarkers. Future Oncol 12 (21):2417-2430. doi:10.2217/fon2016-0178

55. Sidana A, Watson MJ, George AK, Rastinehad AR, Vourganti S, Rais-Bahrami S, Muthigi A, Maruf M, Gordetsky JB, Nix JW, Merino MJ, Turkbey B, Choyke PL, Wood 
BJ, Pinto PA (2018) Fusion prostate biopsy outperforms 12-core systematic prostate biopsy in patients with prior negative systematic biopsy: A multi-institutional analysis. Urol Oncol 36 (7):341 e341-341 e347. doi:10.1016/j.urolonc.2018.04.002 56. Bokhorst LP, Zhu X, Bul M, Bangma CH, Schroder FH, Roobol MJ (2012) Positive predictive value of prostate biopsy indicated by prostate-specific-antigen-based prostate cancer screening: trends over time in a European randomized trial*. BJU Int 110 (11):1654-1660. doi:10.1111/j.1464-410X.2012.11481.x

57. Cormio L, Scattoni V, Lorusso F, Perrone A, Di Fino G, Selvaggio O, Sanguedolce F, Bufo P, Montorsi F, Carrieri G (2014) Prostate cancer detection rates in different biopsy schemes. Which cores for which patients? World J Urol 32 (2):341-346. doi:10.1007/s00345-012-0989-8

58. Abraham NE, Mendhiratta N, Taneja SS (2015) Patterns of repeat prostate biopsy in contemporary clinical practice. J Urol 193 (4):1178-1184. doi:10.1016/j.juro.2014.10.084

59. Simmons LAM, Kanthabalan A, Arya M, Briggs T, Barratt D, Charman SC, Freeman A, Gelister J, Hawkes D, Hu Y, Jameson C, McCartan N, Moore CM, Punwani S, Ramachandran N, van der Meulen J, Emberton M, Ahmed HU (2017) The PICTURE study: diagnostic accuracy of multiparametric MRI in men requiring a repeat prostate biopsy. Br J Cancer 116 (9):1159-1165. doi:10.1038/bjc.2017.57

60. Rosenkrantz AB, Verma S, Choyke P, Eberhardt SC, Eggener SE, Gaitonde K, Haider MA, Margolis DJ, Marks LS, Pinto P, Sonn GA, Taneja SS (2016) Prostate Magnetic Resonance Imaging and Magnetic Resonance Imaging Targeted Biopsy in Patients with a Prior Negative Biopsy: A Consensus Statement by AUA and SAR. J Urol 196 (6):1613-1618. doi:10.1016/j.juro.2016.06.079 61. Auffenberg GB, Lane BR, Linsell S, Brachulis A, Ye Z, Rakic N, Montie J, Miller DC, Cher ML (2017) A Roadmap for Improving the Management of Favorable Risk Prostate Cancer. J Urol 198 (6):1220-1222. doi:10.1016/j.juro.2017.07.085 62. Dieffenbacher S, Nyarangi-Dix J, Giganti F, Bonekamp D, Kesch C, Muller-Wolf MB, Schutz V, Gasch C, Hatiboglu G, Hauffe M, Stenzinger A, Duensing S, Schlemmer HP, Moore CM, Hohenfellner M, Radtke JP (2019) Standardized Magnetic Resonance Imaging Reporting Using the Prostate Cancer Radiological Estimation of Change in Sequential Evaluation Criteria and Magnetic Resonance Imaging/Transrectal Ultrasound Fusion with Transperineal Saturation Biopsy to Select Men on Active Surveillance. Eur Urol Focus. doi:10.1016/j.euf.2019.03.001

63. Da Rosa MR, Milot L, Sugar L, Vesprini D, Chung H, Loblaw A, Pond GR, Klotz L, Haider MA (2015) A prospective comparison of MRI-US fused targeted biopsy versus systematic ultrasound-guided biopsy for detecting clinically significant prostate cancer in patients on active surveillance. J Magn Reson Imaging 41 (1):220-225. 
doi:10.1002/jmri.24710

64. Kaye DR, Qi J, Morgan TM, Linsell S, Ginsburg KB, Lane BR, Montie JE, Cher ML, Miller DC, Michigan Urological Surgery Improvement C (2019) Pathological upgrading at radical prostatectomy for patients with Grade Group 1 prostate cancer:

implications of confirmatory testing for patients considering active surveillance. BJU Int 123 (5):846-853. doi:10.1111/bju.14554

65. Klotz L, Loblaw A, Sugar L, Moussa M, Berman DM, Van der Kwast T, Vesprini D, Milot L, Kebabdjian M, Fleshner N, Ghai S, Chin J, Pond GR, Haider M (2019) Active Surveillance Magnetic Resonance Imaging Study (ASIST): Results of a Randomized Multicenter Prospective Trial. Eur Urol 75 (2):300-309.

doi:10.1016/j.eururo.2018.06.025

66. Klotz L, Pond G, Loblaw A, Sugar L, Moussa M, Berman D, Van der Kwast T, Vesprini D, Milot L, Kebabdjian M, Fleshner N, Ghai S, Chin J, Haider M (2019) Randomized Study of Systematic Biopsy Versus Magnetic Resonance Imaging and Targeted and Systematic Biopsy in Men on Active Surveillance (ASIST): 2-year Postbiopsy Follow-up. Eur Urol. doi:10.1016/j.eururo.2019.10.007

67. Karavitakis M, Winkler M, Abel P, Livni N, Beckley I, Ahmed HU (2011) Histological characteristics of the index lesion in whole-mount radical prostatectomy specimens: implications for focal therapy. Prostate Cancer Prostatic Dis 14 (1):46-52. doi:10.1038/pcan.2010.16

68. Crawford ED, Barqawi A (2007) Targeted focal therapy: a minimally invasive ablation technique for early prostate cancer. Oncology (Williston Park) 21 (1):27-32; discussion 33-24, 39

69. Valerio M, Ahmed HU, Emberton M, Lawrentschuk N, Lazzeri M, Montironi R, Nguyen PL, Trachtenberg J, Polascik TJ (2014) The role of focal therapy in the management of localised prostate cancer: a systematic review. Eur Urol 66 (4):732751. doi:10.1016/j.eururo.2013.05.048

70. Isebaert S, Van den Bergh L, Haustermans K, Joniau S, Lerut E, De Wever L, De Keyzer F, Budiharto T, Slagmolen P, Van Poppel H, Oyen R (2013) Multiparametric MRI for prostate cancer localization in correlation to whole-mount histopathology. J Magn Reson Imaging 37 (6):1392-1401. doi:10.1002/jmri.23938

71. Langley S, Ahmed HU, Al-Qaisieh B, Bostwick D, Dickinson L, Veiga FG, Grimm P, Machtens S, Guedea F, Emberton M (2012) Report of a consensus meeting on focal low dose rate brachytherapy for prostate cancer. BJU Int 109 Suppl 1:7-16.

doi:10.1111/j.1464-410X.2011.10825.x

72. Orczyk C, Rosenkrantz AB, Mikheev A, Villers A, Bernaudin M, Taneja SS, Valable $S$, Rusinek H (2017) 3D Registration of mpMRI for Assessment of Prostate Cancer Focal Therapy. Acad Radiol 24 (12):1544-1555. doi:10.1016/j.acra.2017.06.010 
73. Woodrum DA, Kawashima A, Gorny KR, Mynderse LA (2017) Prostate cancer: state of the art imaging and focal treatment. Clin Radiol 72 (8):665-679. doi:10.1016/j.crad.2017.02.010

74. de Rooij M, Hamoen EH, Witjes JA, Barentsz JO, Rovers MM (2016) Accuracy of Magnetic Resonance Imaging for Local Staging of Prostate Cancer: A Diagnostic Meta-analysis. Eur Urol 70 (2):233-245. doi:10.1016/j.eururo.2015.07.029 75. Rud E, Baco E, Klotz D, Rennesund K, Svindland A, Berge V, Lundeby E, Wessel N, Hoff JR, Berg RE, Diep L, Eggesbo HB, Eri LM (2015) Does preoperative magnetic resonance imaging reduce the rate of positive surgical margins at radical prostatectomy in a randomised clinical trial? Eur Urol 68 (3):487-496.

doi:10.1016/j.eururo.2015.02.039

76. Kozikowski M, Malewski W, Michalak W, Dobruch J (2019) Clinical utility of MRI in the decision-making process before radical prostatectomy: Systematic review and meta-analysis. PLoS One 14 (1):e0210194. doi:10.1371/journal.pone.0210194 77. Ho R, Siddiqui MM, George AK, Frye T, Kilchevsky A, Fascelli M, Shakir NA, Chelluri R, Abboud SF, Walton-Diaz A, Sankineni S, Merino MJ, Turkbey B, Choyke PL, Wood BJ, Pinto PA (2016) Preoperative Multiparametric Magnetic Resonance Imaging Predicts Biochemical Recurrence in Prostate Cancer after Radical Prostatectomy. PLoS One 11 (6):e0157313. doi:10.1371/journal.pone.0157313

78. Babaian RJ, Troncoso P, Bhadkamkar VA, Johnston DA (2001) Analysis of clinicopathologic factors predicting outcome after radical prostatectomy. Cancer 91 (8):1414-1422

79. Patel P, Mathew MS, Trilisky I, Oto A (2018) Multiparametric MR Imaging of the Prostate after Treatment of Prostate Cancer. Radiographics 38 (2):437-449. doi:10.1148/rg.2018170147

80. Gaur S, Turkbey B (2018) Prostate MR Imaging for Posttreatment Evaluation and Recurrence. Urol Clin North Am 45 (3):467-479. doi:10.1016/j.ucl.2018.03.011 81. Cha D, Kim CK, Park SY, Park JJ, Park BK (2015) Evaluation of suspected soft tissue lesion in the prostate bed after radical prostatectomy using 3T multiparametric magnetic resonance imaging. Magn Reson Imaging 33 (4):407-412.

doi:10.1016/j.mri.2014.12.003

82. Barret E, Harvey-Bryan KA, Sanchez-Salas R, Rozet F, Galiano M, Cathelineau X (2014) How to diagnose and treat focal therapy failure and recurrence? Curr Opin Urol 24 (3):241-246. doi:10.1097/MOU.0000000000000052

83. Wegelin O, Exterkate L, van der Leest M, Kummer JA, Vreuls W, de Bruin PC, Bosch J, Barentsz JO, Somford DM, van Melick HHE (2019) The FUTURE Trial: A Multicenter Randomised Controlled Trial on Target Biopsy Techniques Based on Magnetic Resonance Imaging in the Diagnosis of Prostate Cancer in Patients with 
Prior Negative Biopsies. Eur Urol 75 (4):582-590. doi:10.1016/j.eururo.2018.11.040 84. Truong M, Wang B, Gordetsky JB, Nix JW, Frye TP, Messing EM, Thomas JV, Feng C, Rais-Bahrami S (2018) Multi-institutional nomogram predicting benign prostate pathology on magnetic resonance/ultrasound fusion biopsy in men with a prior negative 12-core systematic biopsy. Cancer 124 (2):278-285. doi:10.1002/cncr.31051 85. Tran GN, Leapman MS, Nguyen HG, Cowan JE, Shinohara K, Westphalen AC, Carroll PR (2017) Magnetic Resonance Imaging-Ultrasound Fusion Biopsy During Prostate Cancer Active Surveillance. Eur Urol 72 (2):275-281.

doi:10.1016/j.eururo.2016.08.023

86. Jayadevan R, Felker ER, Kwan L, Barsa DE, Zhang H, Sisk AE, Delfin M, Marks LS (2019) Magnetic Resonance Imaging-Guided Confirmatory Biopsy for Initiating Active Surveillance of Prostate Cancer. JAMA Netw Open 2 (9):e1911019.

doi:10.1001/jamanetworkopen.2019.11019

87. Frye TP, George AK, Kilchevsky A, Maruf M, Siddiqui MM, Kongnyuy M, Muthigi A, Han H, Parnes HL, Merino M, Choyke PL, Turkbey B, Wood B, Pinto PA (2017)

Magnetic Resonance Imaging-Transrectal Ultrasound Guided Fusion Biopsy to Detect Progression in Patients with Existing Lesions on Active Surveillance for Low and Intermediate Risk Prostate Cancer. J Urol 197 (3 Pt 1):640-646.

doi:10.1016/j.juro.2016.08.109

88. Ahdoot M, Wilbur AR, Reese SE, Lebastchi AH, Mehralivand S, Gomella P T, Bloom J, Gurram S, Siddiqui M, Pinsky P, Parnes H, Linehan WM, Merino M, Choyke PL, Shih JH, Turkbey B, Wood BJ, Pinto PA (2020). MRI-Targeted, Systematic, and Combined Biopsy for Prostate Cancer Diagnosis. N Engl J Med 382 (10): 917-928. doi: 10.1056/NEJMoa1910038. 